\title{
PURIFICATION OF ANTI STREPTOCOCCUS GROUP A ANTIBODIES BY AFFINITY CHROMATOGRAPHY AND ISOELECTRIC FOCUSING
}

\author{
by \\ FLEMMING M. POULSEN \\ and \\ JACK T. JOHANSEN \\ Department of Chemistry, Carlsberg Laboratory \\ Gamle Carisberg Vej 10, DK-2500 Copenhagen, Valby
}

Keywords: Immunoadsorbent, isoelectric focusing, $\mathrm{N}$-acetyl-glucosamine, anti Streptococcus group $\mathrm{A}$ antibodies

The synthesis is described of an immunoadsorbent, Sepharose-glycyl-tyrosine-azo-phenyl-N-acetyl-glucosaminide, which specifically absorbs $\mathrm{N}$-acetyl-glucosamine binding proteins. Anti Streptococcus group A antibody populations exhibiting restricted heterogeneity were obtained by affinity gradient elution of the antibodies from this immunoadsorbent. Isoelectric focusing experiments with purified antibody fractions suggested that antibody structures were affected by the experimental conditions used for the preparative isoelectric focusing.

\section{INTRODUCTION}

The occurrence of restricted antibody responses following immunisation with pneumococcal and streptococcal vaccines has in recent years greatly facilitated the isolation of homogeneous antibodies $(10,11)$. KRAUSE has pointed out (7) that an antibody can be regarded as homogeneous when it lacks the manifestations of antibody heterogeneity, such as isotypic variations, allotypic variations, charge heterogeneity and functional heterogeneity. In the design of a purification scheme for the isolation of homogeneous antibodies it is important to perform the purification on the basis of at least two different molecular properties, which would reflect the existence of antibody heterogeneity. In the present work anti Streptococcus group A antibodies have been fractionated on the basis of two physico-chemical characteristics, using 
the combination of affinity chromatography and isoelectric focusing.

The immunogenic component of the streptococcal group A vaccine is a cell wall polysaccharide in which $\mathrm{N}$-acetyl-glucosamine $(\mathrm{NAG})^{1)}$ residues are the important im-<smiles>CONC1(C)OC2(CO)OC1(C)C(C)(O)C2(C)O</smiles>
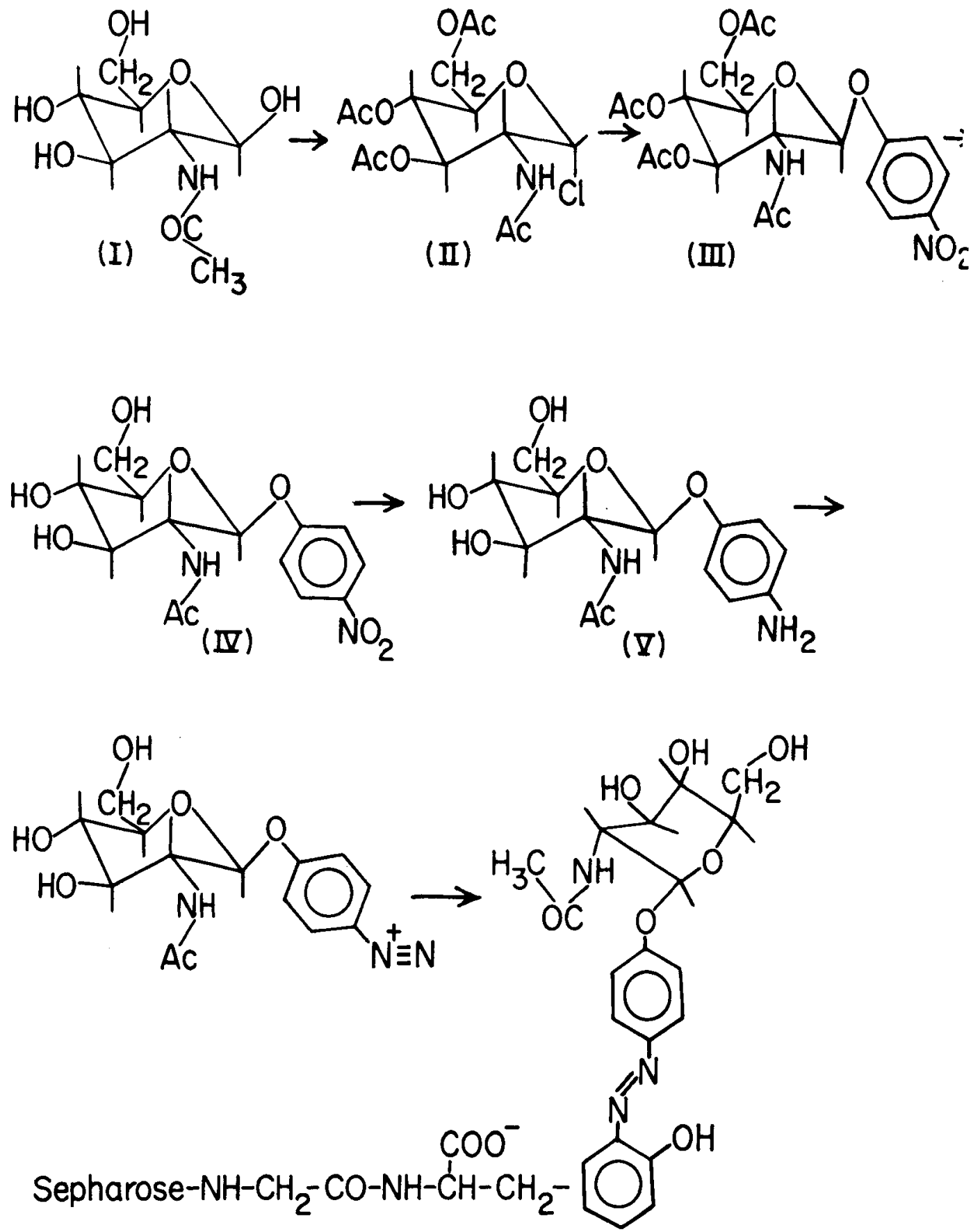

Figure 1. The scheme of synthesis of the Sepharose-gly-tyr-azo-phenyl-NAG immunoadsorbent. (I). is $\mathrm{N}$-acetylglucosaminide, (II) is acetochloroglucosamine, (IIl) is p-nitrophenyl-tetraacetoglucosaminide, (IV) is p-nitrophenyl- $\beta$-D-N-acetylglucosaminide, (V) p-aminophenyl- $\beta-D-N$-acetylglucosaminide. 
munogenic determinants (8). Hence, NAGglucosides could be employed as convenient ligands for an immunoadsorbent. In the present work we have shown that coupling of the NAGglucoside p-amino-phenyl-N-acetyl-glucosaminide to Sepharose-glycyl-tyrosine through an azo-bond yields an useful immunoadsorbent for the isolation of anti Streptococcus group A antibodies. Elution of the antibodies from this absorbent by means of a gradient of NAG and further purification by isoelectric focusing is described as a convenient two step procedure for the isolation of homogeneous antibodies from antisera of restricted heterogeneity.

\section{MATERIALS AND METHODS}

\subsection{Synthesis of the immunoadsorbent}

The method of the synthesis of the immunoadsorbent is schematically shown in Figure 1. p-aminophenyl- $\beta$-D-N-acetyl-glucosaminide $(V)$ was prepared from NAG by reaction with acetylchloride as described by HORTON (6). The resulting acetochloroglucosamine (II) was reacted with sodium p-nitrophenolate (9) to give p-nitrophenyl-tetraacetoglucosaminide (III). This compound was deacetylated in anhydrous methanol by sodium methoxide removing the O-acetyl-groups (14). Reduction of the nitro group was performed by means of hydrogen in the presence of Pd-(barium sulfate) to yield $\mathrm{p}$-aminophenyl- $\beta$-D-N-acetyl-glucosaminide (V) (14).

Sepharose was activated with cyanogen bromide and coupled with glycyl-tyrosine essentially as described by CuATRECASAS (2). The affinity gel was obtained by diazotisation of $\mathrm{p}$ aminophenyl- $\beta-\mathrm{D}-\mathrm{N}$-acetyl-glucosaminide and coupling of this derivative to Sepharose-glycyltyrosine. $6 \mathrm{ml}$ of $1 \mathrm{M}-\mathrm{HCl}\left(0^{\circ} \mathrm{C}\right)$ was added to $1 \mathrm{~g}$ of $\mathrm{p}$-aminophenyl- $\beta$ - $\mathrm{D}-\mathrm{N}$-acetyl-glucosaminide (V) dissolved in $10 \mathrm{ml}$ of water at $0^{\circ} \mathrm{C}$ and subsequently an equimolar amount of sodium nitrite was added. After 10 minutes of reaction at $0^{\circ} \mathrm{C}$ the $\mathrm{pH}$ was adjusted to 7 with 2 $\mathrm{M}-\mathrm{NaOH}$ and the reaction mixture was immediately added to a suspension of $300 \mathrm{ml}$ packed Sepharose-glycyl-tyrosine in $200 \mathrm{ml}$ of 0.1 M-sodium bicarbonate, $\mathrm{pH} 9.2$ at $0^{\circ} \mathrm{C}$. The $\mathrm{pH}$ was maintained at this value until the up- take of alkali ceased. The reaction mixture was then kept at $4^{\circ} \mathrm{C}$ for 3 hours and subsequently washed several times with water.

\subsection{Affinity chromatography}

Affinity chromatography experiments with the immunoadsorbents were carried out in Pharmacia columns K 16/30 containing $45 \mathrm{ml}$ of resin. Samples of serum (app. $10 \mathrm{ml}$ ) were passed through the column and unbound serum proteins were eluted with PBS pH 7.4. Bound antibodies were eluted with either $10 \%(w / v)$ NAG in PBS or $1 \mathrm{M}$-propionic acid or $200 \mathrm{ml}$ of a linear gradient from 0 to $10 \%$ NAG in PBS. The flow rate was $30 \mathrm{ml}$ per hour.

\subsection{Analysis of the L-chain composition}

Antibodies were reduced and alkylated using the method described by REISFIELD \& SMALL (12). They were subsequently analysed by disc gel electrophoresis in polyacrylamide gels containing $10 \mathrm{M}$-urea (12). The polyacrylamide gels consisted of both a spacer and a separating gel and were prepared according to the procedure described by the authors mentioned above (12). After electrophoresis the proteins were fixed in the gels by TCA for $30 \mathrm{~min}$, and the gels were then washed with $7 \%$ acetic acid prior to staining in $0.05 \%$ amido black for 1 hour. Excess of stain was removed by electrophoretic destaining.

\subsection{Analytical isolelectric focusing}

Isoelectric focusing in polyacrylamide gel plates was performed using the LKB Multiphor system and the prescriptions recommended by the manufacturer were followed. The $\mathrm{pH}$-gradients in the gel plates were in all cases established employing carrier ampholytes in the $\mathrm{pH}$-range 3 to 10 . Protein bands in the polyacrylamide gel were visualized by fixation of the protein by TCA.

\subsection{Preparative isoelectric focusing}

Preparative isoelectric focusing in vertical sucrose gradients was performed employing the 
LKB Uniphor system 8101 . The preparation of the sucrose gradient, the electrophoretic set up, the $\mathrm{pH}$-gradient and elution from the column was performed as described by the manufacturer. Carrier ampholytes at a concentration of $1 \%$ and covering the $\mathrm{pH}$ range 5 to 8 were employed. The electrofocusing time was 36 hours unless specified. The experiments were performed at $4^{\circ} \mathrm{C}$ and a constant voltage of $1100 \mathrm{~V}$.

\subsection{Microzone electrophoresis}

Rabbit antisera and antibody fractions were analysed by microzone electrophoresis performed in cellulose acetate membrane. The experiments were performed and recorded as described by AASTED (1).

\subsection{Immunoelectrophoresis}

Rabbit serum proteins were detected by immunoelectrophoresis using swine immunoglobulins against rabbit serum proteins (DAKO immunoglobulins, Copenhagen).

\subsection{Single radial immunodiffusion}

Antibodies were quantitated by radial diffusion into agarose containing Streptococcus group A polysaccharide (1). The polysaccharide was prepared by formamide extraction from the cells according to the method of FULlER (4).

\subsection{Quantitation of protein}

The biuret method was used for measuring protein concentrations (5). Optical densities at $280 \mathrm{~nm}$ were also used for determinations of IgG concentrations in purified fractions employing an $E_{280}^{1 \%}=14.0(13)$.

\subsection{Antisera against Streptococcus group $A$ antigens}

The production of antisera has been described previously $(1,7)$. The antisera were all obtained from a group of rabbits hyperimmunised to produce homogeneous antibodies.

\section{RESULTS}

\subsection{Binding of antibodies to the immunoadsorbent}

Chromatography of a sample of Streptococcus group A antiserum on a column of the immunoadsorbent demonstrated that the antibodies were adsorbed since no antibody activity could be determined in the effluent as measured by the radial immunodiffision test. The capacity of the column was 8 to $13 \mathrm{mg}$ per $\mathrm{ml}$ of packed immunoadsorbent. Antibodies adsorbed to the gel could be eluted with $10 \%$ (w/v)-NAG in PBS (Fig. 2). Similarly $1 \mathrm{M}$ propionic acid was a very effective eluant, whereas $1 \mathrm{M}$-acetic acid and $3 \mathrm{M}$-sodium chloride appeared to be poor eluants.

Immunoelectrophoresis of the eluted proteins (Fig. 2, fraction II) showed that these were rabbit $\mathrm{IgG}$. Only in few cases a trace amount of rabbit IgM was present in the eluates. It was confirmed that the IgG fraction was anti Streptococcus group A antibodies by single radial immunodiffusion in agarose containing Streptococcus group A polysaccharide.

\subsection{Gradient elution of antibodies from individual sera}

Affinity chromatography of various in. dividual antisera were performed employing linear NAG-gradients. Rechromatography of pooled fractions from such experiments demonstrated that the elution volume in the

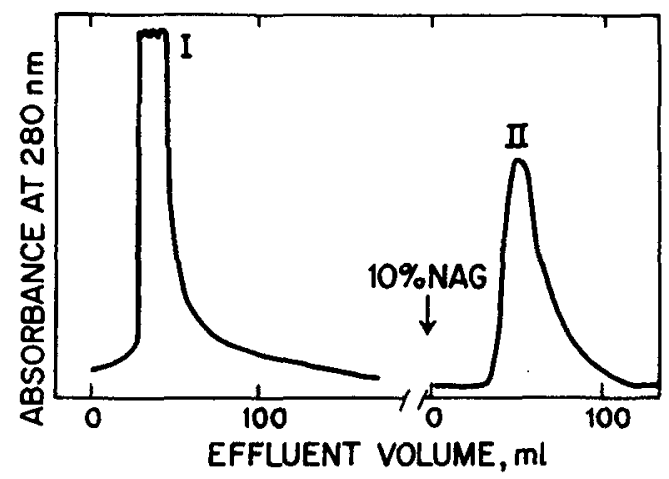

Figure 2. Isolation of anti Streptococcus group A antibodies by affinity chromatography on Sepharose-gly-tyr-azo-phenyl-NAG. Rabbit antiserum $(10 \mathrm{ml})$ was applied to the column $(1.6 \times 15.0 \mathrm{~cm})$. PBS at $\mathrm{pH}$ 7.4 was employed for elution of non-bound materials, peak I. Elution with $10 \%$ NAG released the specifically bound antibodies, peak II (see text). 


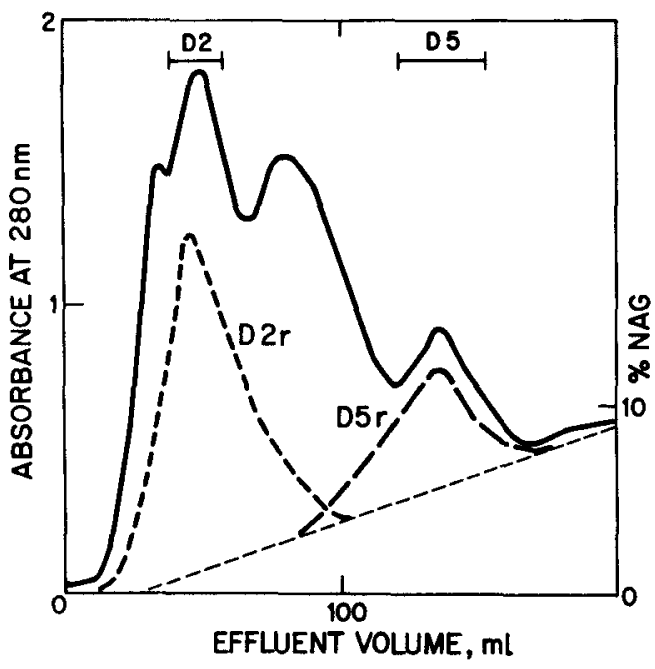

Figure 3. Gradient elution of antibodies employing a linear gradient of NAG from 0 to $10 \%$. The pooled fractions D2 and D5 have been separately rechromatographed on the same column, using the previous gradient. (-) shows the chromatogram of the whole antibody population. (----) shows the rechromatography of the fractions D2 and D5 (as indicated by $\mathrm{D} 2 \mathrm{r}$ and $\mathrm{D} 5 \mathrm{r}$ ). (---_---) denotes the NAG gradient absorption at $280 \mathrm{~nm}$.

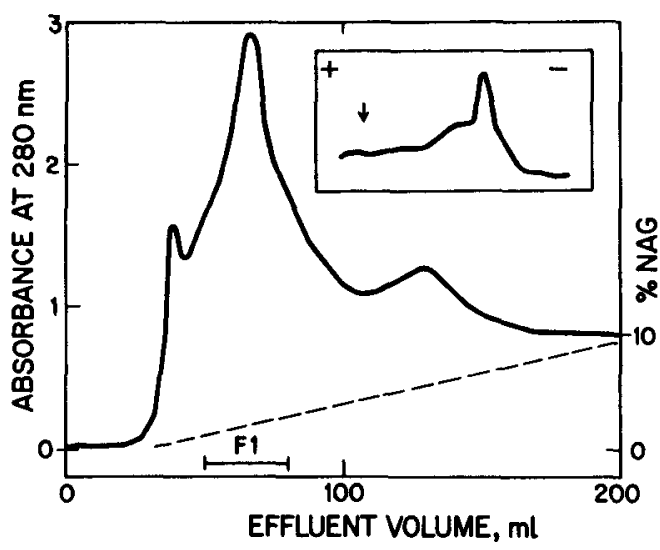

Figure $4 \mathrm{~A}$ :. Elution from the immunoadsorbent of anti Streptococcus group $\mathbf{A}$ antibodies from serum batch 4421 . The bar indicate which fractions were pooled. The absorbance at $280 \mathrm{~nm}$ of NAG is indicated by (--_). The insert shows the zone electrophoresis record of the gamma band of the applied serum. Both methods indicate that the antibody population of this serum contain a highly abundant subpopulation.
NAG-gradient of a given fraction of the antibody population was identical with that of the first fractionation (Fig. 3). This indicates that the point of elution of an antibody under such conditions is a suitable parameter for the description of an antibody in terms of affinity, and the chromatogram of an affinity gradient
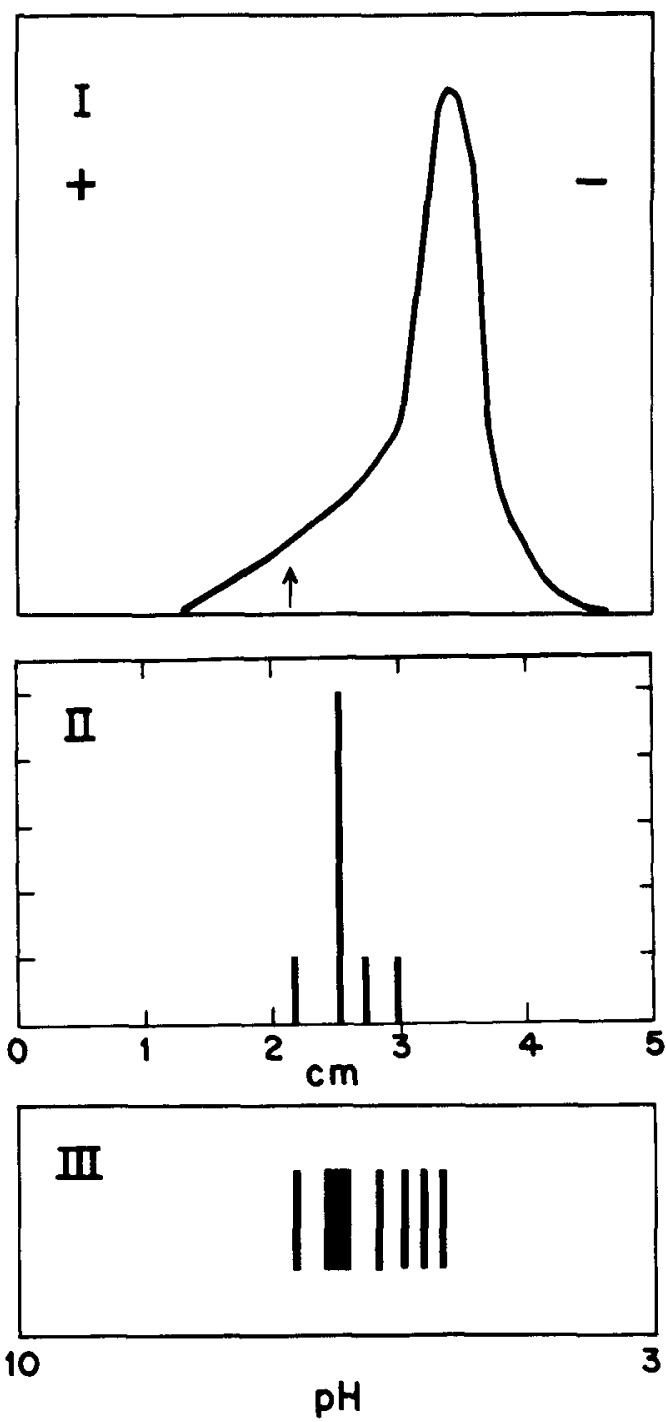

B: Analysis of the pooled fraction F 1 from Fig. 4 A by zone electrophoresis (I), disc gel electrophoresis of the alkylated L-chains (II) and isoelectrofocusing (III). In II: The position of the lines on the abscissa indicate the mobility of the light chains in the small pore gel in $\mathrm{cm}$. The heights indicate the intensity of the lines in arbitrary units as observed by visual inspection. In I: The arrow indicate the point of application. 
experiment would reflect the composition of an antibody population in terms of affinity. Antibody populations are commonly characterized by their electrophoretical mobilities as observed by zone electrophoresis. For this reason the gradient affinity chromatograms of individual antisera were compared with their zone electrophoresis diagrams. A correlation between these two methods was found, since antibody populations containing an abundant component of one particular electrophoretical mobility, also dis-

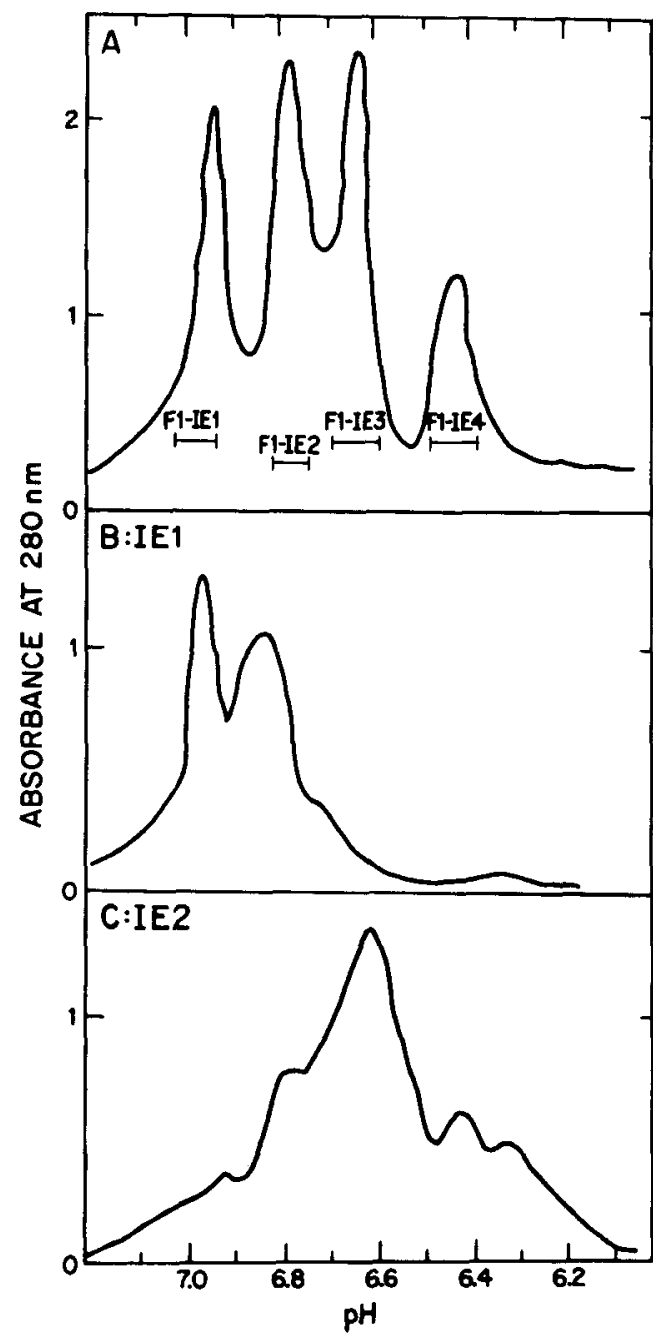

Figure 5. Preparative isoelectric focusing of fraction $\mathrm{F} 1$ (Fig. $4 \mathrm{~A}$ ) and reelectrophocusing of the fractions $\mathrm{F} 1$ - IE 1 (B) and F 1 - IE 2 (C). The absorbance is plotted versus $\mathrm{pH}$ to facilitate comparisons of the chromatograms. Time of electrofocusing was 36 hours, and the $\mathrm{pH}$-gradient was from 5 to 8 . played an abundant component in terms of affinity (Fig. $4 \mathrm{~A}$ ). The composition of the fraction was further examined by disc gel electrophoresis of the alkylated L-chain and analytical isoelectric focusing of the intact antibodies. The light chain of the antibodies in fraction $F 1$ is seen to be made up predominantly of a single component (Fig. 4 B, II) and a weak background of other light chains. Analytical isoelectric focusing and zone electrophoresis of the intact IgG molecules support the result of the disc gel electrophoresis as seen in Fig. 4 B.

\subsection{Preparative isoelectric focusing}

In order to achieve further fractionation of the antibody populations obtained by affinity gradient elution, these were fractionated by preparative isoelectric focusing. In Fig. $5 \mathrm{~A}$ is shown the isoelectric focusing elution pattern of the affinity subpopulation of the F 1 pool from Fig. $4 \mathrm{~A}$. This chromatogram is seen to contain four major peaks eluted at $\mathrm{pH} 6.90$ 6.95 (F 1 - IE 1), $\mathrm{pH} 6.75$ - 6.80 (F 1 - IE 2), $\mathrm{pH}$ $6.60-6.65$ (F 1 - IE 3) and pH $6.45-6.40$ (F 1 IE 4) of the gradient. Reelectrofocusing experiments were performed with the pooled fractions of peaks F 1 - IE 1 and F 1 - IE 2, respectively. The elution chromatograms are shown in Fig 5 B and C and it is seen that the reelectrofocusing has displaced the positions of the peaks. In case of peak Fl - IE 1 reelectrofusing changed its isoelectric point from between pH 6.90-6.95 to two major bands (Fig. $5 \mathrm{~B}$ ) the original and a new one, having an isoelectric point between $\mathrm{pH} 6.75-6.80$. Two additional smaller peaks at $\mathrm{pH} 6.60-6.65$ and at $6.40-6.30$ could be seen as well. The position of fraction F 1 - IE 2 was also changing upon reelectrofocusing. This peak, which in the original experiment was eluted in a fraction of isoelectric point at $\mathrm{pH} 6.75-6.80$ was almost completely displaced to $\mathrm{pH}$ values of $6.60-6.65$ of the $\mathrm{pH}$-gradient and also to values of $\mathrm{pH} 6.40$ - 6.30. A similar observation was made when another antibody population purified by affinity chromatography (fraction D2r, Fig. 3) was run in a preparative isoelectric focusing experiment. After 36 hours of electrofocusing a 


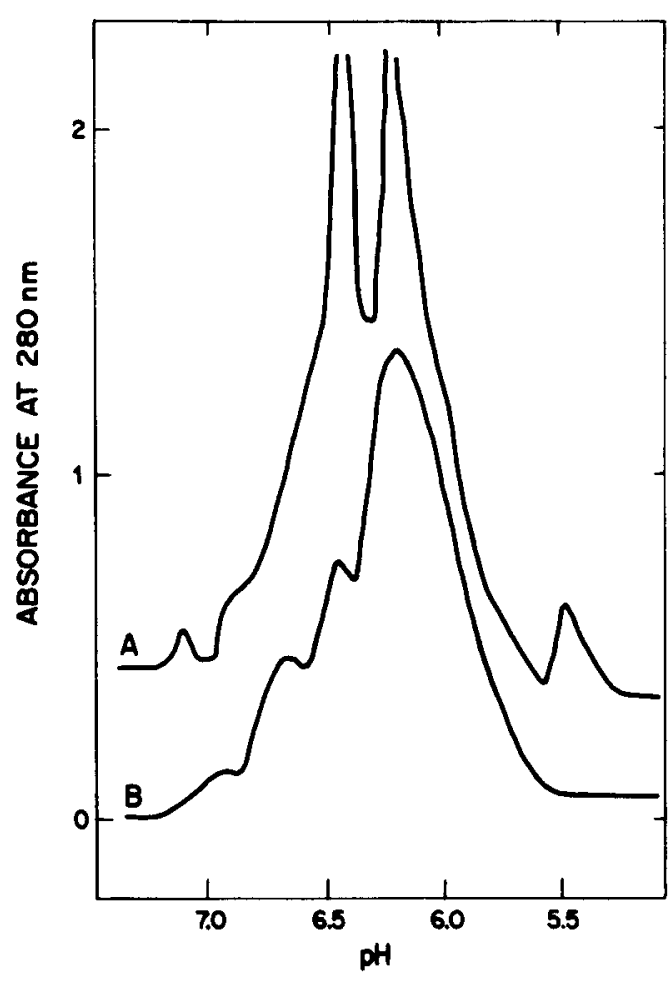

Figure 6. Preparative isoelectric focusing of an antibody fraction purified by affinity chromatography, frac. D2 r, Figure 3. In (A) time of electrofocusing was 36 hours. In (B) time of electrofocusing was 72 hours.

chromatogram was obtained as shown in Fig. 6 A. This chromatogram exhibits two major peaks with isoelectric points of $6.45-6.40$ and 6.30 - 6.25. However, when the time of electrofocusing was extended to 72 hours, Fig. $6 \mathrm{~B}$, the $\mathrm{pH} 6.45-6.40$ peak had disappeared almost completely, whereas that of the $\mathrm{pH} 6.30$ - 6.25 peak had increased. It seems obvious from these findings that antibodies under the conditions of an isoelectric focusing experiment are undergoing changes which decrease their isoelectric points.

\section{DISCUSSION}

In the present work we have described the synthesis of a new immunoadsorbent for the isolation of anti Streptococcus group A antibodies. Immunoadsorbents which bind anti Streptococcus group A antibodies have previously been described $(3,16)$. The major difference between these immunoadsorbents and the present one is the very hydrophobic phenyl-azo-tyrosyl spacer between the carrier and the hapten NAG. The findings that propionic acid is more effective than the less hydrophobic acetic acid in releasing antibodies from the immunoadsorbent and the failure of $3 \mathrm{M}-\mathrm{NaCl}$ as an eluant suggest that hydrophobic interactions might play an important role for the binding of antibodies to this immunoadsorbent. An immunoadsorbent in which Streptococcus group $\mathrm{C}$ polysaccharide was bound directly to the gel was reported to release bound antibodies when sodium chloride and acetic acid were employed as eluants (3). Thus we assume that the hydrophobic spacer phenyl-azo-tyrosine cooperates in the binding of the antibodies to the present immunoadsorbent.

Affinity gradient elution of antibodies is not a very selective fractionation method since the separation of species depends on differences in their affinities which might be very small. We have examined the ability of the immunoadsorbent to fractionate antibody populations of very different composition and it was demonstrated that the isolation of a single component from complex mixtures of antibodies was not possible with our methodology. However, in cases where one component is highly abundant the isolation of this component becomes a much simpler task, as demonstrated by the isolation of a single component of serum 4421 (Fig. 4).

The resolving power of isoelectric focusing makes this technique well suited for fractionation of heterogeneous antibody populations. However, since the method is very sensitive to even small differences in charges the problem of microheterogeneity has to be considered. Biosynthetically homogeneous antibodies have been shown to undergo postsynthetic changes, which cause alterations of charges in the protein (15). Even homogeneous antibodies might therefore be fractionated into several species when isoelectric focusing is applied as a fractionating method. The origin of this microheterogeneity is not well understood, and several molecular events might account for the phenomenon such as allomorphism, deamida- 
tion, differences in $\mathrm{N}$-terminal amino acid residues, partial degradation of carbohydrate chains and binding of ligands (15).

In our attempts to isolate homogeneous antibodies by isoelectric focusing we have observed that antibodies undergo changes which decrease their pl-values. The reason for this behaviour is difficult to explain. It seems likely, however, that one or several of the mechanisms discussed above, might account for this phenomenon. The observed changes could have been caused by any of the electrofocusing conditions or they might simply be a result of storage. For two reasons we find it most likely to assume that the changes occured as a result of electrofocusing. Firstly, the demonstration that one component disappeared almost completely, when the time of focusing was extended to 72 hours seems to support this assumption (Fig. 6). Secondly, all fractions were stored at $-18^{\circ}$ until the experiments were performed, and it is most unlikely that any of the processes mentioned above would take place under that condition. These processes might also account for the many bands observed by analytical isoelectric focusing experiments. These bands might reflect postsynthetic changes of the antibodies, which occurred in the living animal. However, since changes of the charges of these antibodies seem to take place during the preparative isoelectric focusing experiments it is possible that similar changes could take place, when such experiments are performed in polyacrylamide gels. The appearance of four bands observed in the analysis of fraction $F 1$ using isoelectric focusing in polyacrylamide plates, seems to indicate that a change of charges similar to the one observed by preparative isoelectric focusing is occuring.

By the two step purification procedure described in the present work we intended to isolate a homogeneous antibody. The antibodies which have been isolated had the following properties. They were highly abundant in the serum from which they were isolated. The high abundance was primarily detected by zone electrophoresis, which indicated the presence of antibodies of one particular electrophoretical mobility in high concentration. Subjected to gradient affinity elution this antibody population was fractionated into affinity subpopulations. The appearance of one highly abundant affinity subpopulation was consistent with the previous finding. Further analysis of this population demonstrated that it contained two major components of slightly different pl-values. The electrophoretical mobilities of the light chains of these antibodies were examined by disc gel electrophoresis, (Fig 4 B), and they were shown to contain one light chain type in a very high concentration. Further fractionation of this affinity subpopulation by isoelectric focusing demonstrated the presence of four different species of antibodies. However, since the refocusing experiments indicated that these four species were artefacts of the fractionation method, we assume that they may have the same molecular origin. This assumption is based on the observation that these four types of antibodies have a common light chain type. Thus, it seems most likely that the isolated antibodies originally were biosynthetically homogeneous.

\section{ACKNOWLEDGEMENTS}

The authors would like to thank Dr. B. AASTED for the supply of anti Streptococcus group A antisera. We are indebted to Professor M. OTtESEN for helpful criticism during the preparation of the manuscript. Part of this work was supported by the National Research Council of Denmark to F. M. POuLSEN. Finally, the financial support of the Carlsberg Brewery is gratefully acknowledged.

\section{REFERENCES}

1. AASTED, B: Characterisation of the antibody production in rabbits induced by streptococcal group $A$ and $C$ Antigens. Scand. J. Immunol. 3, 545-552 (1974)

2. Cuatrecasas, P.: Protein purification by affinity chromatography. 3. Biol. Chem. 245, 3059-3065 (1970)

3. Eichmann, K. \& J. Greendlatt: Relationship 
between relative binding affinity and electrophoretic behaviour of antibodies to streptococcal carbohydrates. J. Exp. Med. 133, 424-441 (1971)

4. Fuller, A. T.: The formamide method for the extraction of polysaccharides from haemolytic streptococci. Brit. J. Ex. Path. 19, 130-136 (1938)

5. Gornall, A. G., E. J. Bardawill \& M. M. DAvID: Determination of serum proteins by means of the biuret reaction. J. Biol. Chem. 177, 751-766 (1949)

6. Horton, D.: 2-acetamido-3, 4, 5-tri-O-acetyl-2deoxy-glucopyranosyl chloride. In: E. J. Corey, ed., Organic Synthesis, vol. 46, 1-4, John Wiley and Sons (1966)

7. Krause, R. M:: The search for antibodies with molecular uniformity. Advances in Immunology. $12,1-56(1970)$

8. Krause, R. M. \& M. McCarthy: Studies on the chemical structure of the streptococcal cell wall. J. Exp. Med. 115, 49-62 (1962)

9. LeabaCk, D. H. \& P. G. WalkeR: The preparation and properties of acetochloroglucosamine and its use in the synthesis of 2-acetamido-2-deo- xy- $\beta$-D-glucosides. J. Chem. Soc., 4794-4760 (1957)

10. Osterland, C. K., E. J. Miller, W. W. KaRAKAwa \& R. M. KRAUSE: Characteristics of streptococcal group-specific antibody isolated from hyperimmune rabbits. J. Exp. Med. 123, 599-614 (1966)

11. Pincus, J. H., J. C. Jaton, J. J. Bloch \& E. HABER: Properties of structurally restricted antibody to type VIII pneumococcal polysaccharide. J. Immunol. 104, 1143-48 (1970)

12. Reisfeld, R. A. \& P. A. Small: Electrophoretic heterogeneity of polypeptide chains of specific antibodies. Science. 152, 1253-1256 (1966)

13. PORTER, R. R.: The hydrolysis of $\gamma$-globuline and antibodies by crystalline papain. Biochem. J. 73, 119-127(1959)

14. Westphal, O. \& H. SChmidt: N-acetyl-glucosamide als determinante Gruppe in künstlichen Antigegen. Ann. Chem. 575, 84-90(1952)

15. Williamson, A. R., M. R. Salaman \& H. W. KRETH: Microheterogeneity and allmomorphism of proteins. Ann. N. Y. Acad. Sci. 209, 210-224 (1973) 